\title{
PET imaging of soluble epoxide hydrolase in non-human primate brain with $\left[{ }^{18} \mathrm{~F}\right] \mathrm{FNDP}$
}

Yong Du* ${ }^{*}$, II Minn, Catherine Foss, Wojciech G. Lesniak, Feng Hu, Robert F. Dannals, Martin G. Pomper and Andrew G. Horti ${ }^{*}$ (D)

\begin{abstract}
Purpose: Soluble epoxide hydrolase $(\mathrm{SEH})$ is a promising candidate positron emission tomography (PET) imaging biomarker altered in various disorders, including vascular cognitive impairment (VCl), Alzheimer's disease (AD), Parkinson's disease (PD), stroke, and depression, known to regulate levels of epoxyeicosatrienoic acids (EETs) and play an important role in neurovascular coupling. $\left.{ }^{18} \mathrm{~F}\right] \mathrm{FNDP}$, a PET radiotracer for imaging $\mathrm{sEH}$, was evaluated through quantitative PET imaging in the baboon brain, radiometabolite analysis, and radiation dosimetry estimate.

Methods: Baboon $\left[{ }^{18}\right.$ F]FNDP dynamic PET studies were performed at baseline and with blocking doses of the selective sEH inhibitor AR-9281 to evaluate $\mathrm{sEH}$ binding specificity. Radiometabolites of $\left[{ }^{18} \mathrm{~F}\right] \mathrm{FNDP}$ in mice and baboons were measured by high-performance liquid chromatography. Regional brain distribution volume $\left(V_{T}\right)$ of $\left[{ }^{18}\right.$ F]FNDP was computed from PET using radiometabolite-corrected arterial input functions. Full body distribution of $\left[{ }^{18} \mathrm{~F}\right] \mathrm{FNDP}$ was studied in CD-1 mice, and the human effective dose was estimated using OLINDA/EXM software.
\end{abstract}

Results: $\left[{ }^{18} \mathrm{~F}\right] \mathrm{FNDP}$ exhibited high and rapid brain uptake in baboons. AR-9281 blocked $\left[{ }^{18} \mathrm{~F}\right] \mathrm{FNDP}$ uptake dose-dependently with a baseline $V_{T}$ of $10.9 \pm 2.4 \mathrm{~mL} / \mathrm{mL}$ and a high-dose blocking $V_{T}$ of $1.0 \pm 0.09 \mathrm{~mL} / \mathrm{mL}$, indicating substantial binding specificity $(91.70 \pm 1.74 \%)$. The $V_{\text {ND }}$ was estimated as $0.865 \pm 0.066 \mathrm{~mL} / \mathrm{mL}$. The estimated occupancy values of AR-9281 were $99.2 \pm 1.1 \%$ for $1 \mathrm{mg} / \mathrm{kg}, 88.6 \pm 1.3 \%$ for $0.1 \mathrm{mg} / \mathrm{kg}$, and $33.8 \pm$ $3.8 \%$ for $0.02 \mathrm{mg} / \mathrm{kg}$. Murine biodistribution of $\left[{ }^{18} \mathrm{~F}\right] \mathrm{FNDP}$ enabled an effective dose estimate for humans $(0.032 \mathrm{mSv} / \mathrm{MBq})$. $\left.{ }^{18} \mathrm{~F}\right] \mathrm{FNDP}$ forms hydrophilic radiometabolites in murine and non-human primate plasma. However, only minute amounts of the radiometabolites entered the animal brain ( $<2 \%$ in mice).

Conclusions: $\left[{ }^{18} \mathrm{~F}\right] \mathrm{FNDP}$ is a highly sEH-specific radiotracer that is suitable for quantitative PET imaging in the baboon brain. $\left[{ }^{18} \mathrm{~F}\right] \mathrm{FNDP}$ holds promise for translation to human subjects.

Keywords: sEH, Positron emission tomography, Central nervous system, Papio anubis, $\left.{ }^{18} \mathrm{~F}\right] \mathrm{FNDP}$

\footnotetext{
*Correspondence: duyong@jhu.edu; ahorti1@jhmi.edu

Division of Nuclear Medicine and Molecular Imaging, The Russell H. Morgan Department of Radiology and Radiological Science, The Johns Hopkins University School of Medicine, 601 North Caroline Street, JHOC 3223, Baltimore, MD 21287, USA
}

\section{Springer Open}

(c) The Author(s). 2020 Open Access This article is licensed under a Creative Commons Attribution 4.0 International License, which permits use, sharing, adaptation, distribution and reproduction in any medium or format, as long as you give appropriate credit to the original author(s) and the source, provide a link to the Creative Commons licence, and indicate if changes were made. The images or other third party material in this article are included in the article's Creative Commons licence, unless indicated otherwise in a credit line to the material. If material is not included in the article's Creative Commons licence and your intended use is not permitted by statutory regulation or exceeds the permitted use, you will need to obtain permission directly from the copyright holder. To view a copy of this licence, visit http://creativecommons.org/licenses/by/4.0/. 


\section{Introduction}

Soluble epoxide hydrolase $(\mathrm{sEH})$ catalyzes the hydrolysis of epoxyeicosatrienoic acids (EETs) to the corresponding diols with reduced biological activity. EETs play an important role in vasodilation of cerebral blood vessels that accompany neuronal activity, i.e., neurovascular coupling [1-3]. Accordingly, sEH is important in cerebrovascular pathophysiology in the context of mild cognitive impairment, vascular cognitive impairment (VCI), Alzheimer's disease (AD), stroke, stress, depression, and other conditions [4, 5]. Post-mortem and animal studies have shown increased levels of expression of cerebral sEH in age-related VCI [4], anorexia [6], depression [5, 7], bipolar disorder [5], schizophrenia [5], Parkinson's disease $[5,8,9]$, and dementia with Lewy bodies [5, 10, 11]. Imaging of $\mathrm{sEH}$ using positron emission tomography (PET) may shed light on those disorders as well as on normal brain function, particularly with respect to neurovascular coupling.

PET imaging of sEH may also prove useful to study target engagement and other aspects of $\mathrm{sEH}$ drug candidates for treatment of pain, inflammation, hypertension, and numerous other conditions [12-15]. Perhaps most significantly, PET imaging of sEH may enhance our understanding of the pathophysiology of vascular disease that occurs in MCI and AD [16]. Combined with existing imaging agents for amyloid and tau, PET imaging of sEH may provide complementary mechanistic information for the noninvasive methods by which to understand the neurobiology of dementia $[17,18]$.

We have recently developed a potent $\mathrm{SEH}$ inhibitor FNDP. Radiolabeled $\left[{ }^{18} \mathrm{~F}\right] \mathrm{FNDP}$ is the first PET radiotracer for specific imaging of $\mathrm{sEH}$ [19]. Our previous studies have demonstrated that $\left[{ }^{18} \mathrm{~F}\right]$ FNDP readily entered the mouse [ $5 \%$ injected dose per gram (ID/g) of tissue] and baboon (standardized uptake value, SUV =4) brain, binding $\mathrm{sEH}$ with high specificity in self-blockade experiments $(\sim 95 \%)$.

To confirm the very high binding specificity of $\left[{ }^{18} \mathrm{~F}\right] \mathrm{FNDP}$ to $\mathrm{sEH}$ and its promising in vivo imaging properties, we performed extensive baboon PET imaging studies (baseline and dose-escalation blockade with selective sEH inhibitor AR-9281) (Fig. 1), quantification of $\left[{ }^{18} \mathrm{~F}\right] \mathrm{FNDP}$ radiometabolites in murine and baboon plasma and brain, and whole body biodistribution in mice to provide estimates of radiation burden to the human body.

\section{Materials and methods}

All experimental animal protocols were performed in accordance with relevant federal and state laws and institutional guidelines and approved by the Animal Care and Use Committee of the Johns Hopkins Medical Institutions.

\section{Chemicals}

AR-9281, a potent and selective sEH inhibitor [14, 20-23] tested in Phase 2 human trial (ClinicalTrials.gov identifier: NCT00847899), was synthesized in-house as described previously [22]. $\left[{ }^{18} \mathrm{~F}\right]$ FNDP was radiolabeled as described previously $[19,24]$.

\section{Baboon PET imaging}

PET images were acquired using a CPS/CTI highresolution research tomograph (HRRT), which has an axial resolution (FWHM) of $2.4 \mathrm{~mm}$ and in-plane resolution of 2.4-2.8 mm [25]. The baseline studies were performed on three male baboons (Papio anubis) weighing $22-26 \mathrm{~kg}$ and the dose-escalation blocking scans with AR-9281 were performed on one of these animals. These blocking studies were performed 27 to 43 days apart from each other to ensure full animal recovery. The animals had no food for $12 \mathrm{~h}$ prior to each PET study. Anesthesia was induced with intramuscular ketamine $(7.5-10 \mathrm{mg} / \mathrm{kg})$ and maintained with a continuous intravenous infusion of propofol at $0.3-0.4 \mathrm{mg} / \mathrm{kg} / \mathrm{min}$ throughout the PET experiment. One venous catheter was inserted for the radioligand injection, and one arterial catheter was inserted to obtain arterial blood samples. Baboons were intubated to facilitate respiration, and circulatory volume was maintained by constant infusion of isotonic saline. Physiological vital signs including heart rate, blood pressure, electrocardiogram, and oxygen saturation were monitored continuously throughout the study.

The animals were positioned in the PET scanner with the head immobilized using a thermoplastic mask. A 6min transmission scan was acquired using a rotating<smiles>O=C(NCCC(c1ccccc1)c1ccccc1)c1ccc(F)nc1</smiles><smiles>CC(=O)N1CCC(NC(=O)NC23CC4CC(CC(C4)C2)C3)CC1</smiles>

AR-9281

Fig. 1 Structures of $\left[{ }^{18}\right.$ F]FNDP and AR-9281 
${ }^{137}$ Cesium source for generating attenuation maps. The 90-min dynamic PET acquisition was then started in three-dimensional list mode simultaneously with an intravenous bolus injection of $\left[{ }^{18} \mathrm{~F}\right] \mathrm{FNDP}$. For the three blocking studies in the same animal, AR-9281 was given subcutaneously $1 \mathrm{~h}$ before the intravenous bolus injection of $\left[{ }^{18} \mathrm{~F}\right] \mathrm{FNDP}$ and the start of the dynamic scan. Table 1 provides experimental details of the PET studies.

\section{Input function and radiometabolite analysis}

Measurement of the arterial plasma input function was conducted through collection of $\sim 40$ blood samples over the course of the 90-min dynamic PET study. Blood samples were obtained via the arterial catheter at continually prolonged intervals, as rapidly $(<5 \mathrm{~s})$ as possible for the first $90 \mathrm{~s}$, with samples acquired at increasingly longer intervals thereafter. Samples were then centrifuged at $1200 \times g$, and the plasma radioactivity was measured with a cross-calibrated PerkinElmer Wizard 2480 automatic gamma counter.

Select plasma samples $(0,5,10,20,30,60$, and $90 \mathrm{~min})$ were analyzed for radiometabolites using highperformance liquid chromatography (HPLC). The modified column-switching HPLC method was used [26]. The HPLC system consisting of a 1260 infinity quaternary pump, a 1260 infinity column compartment module, a 1260 infinity UV detector, and a Raytest GABI Star radiation detector, was operated with OpenLab CDS EZChrom (A.01.04) software. A 0.4-1.5-mL sample of plasma was loaded into a 2-mL Rheodyne injector loop and initially directed to the capture column (packed with Phenomenex Strata-X $33 \mu \mathrm{m}$ polymeric reversed phase sorbent) and both detectors with $1 \%$ acetonitrile and $99 \%$ water mobile phase at $2 \mathrm{~mL} / \mathrm{min}$. After $1 \mathrm{~min}$ of isocratic elution, analytical mobile phase composed of $65 \%$ acetonitrile and $35 \%$ water with $0.06 \mathrm{M}$ trimethylamine (at $\mathrm{pH}=7.2$, adjusted with phosphoric acid) was applied to direct non-polar compounds trapped on the capture column to an analytical column (Gemini C18(2), $10 \mu \mathrm{m}, 4.6 \times 250 \mathrm{~mm}$ ) and detectors at $2 \mathrm{~mL} / \mathrm{min}$. The HPLC system was standardized for mass using nonradioactive FNDP prior to analysis of the blood plasma samples, which were spiked with $5 \mu \mathrm{L}$ of non-radioactive FNDP at a concentration of $1 \mathrm{mg} / \mathrm{mL}$.

\section{Murine radiometabolite analysis}

Male CD-1 mice (25-26 g) were injected via the lateral tail vein with $37 \mathrm{MBq}$ of high specific activity $(1.1 \mathrm{TBq} / \mu \mathrm{mol}$ or $29.7 \mathrm{Ci} / \mu \mathrm{mol})\left[{ }^{18} \mathrm{~F}\right] \mathrm{FNDP}$. The mice were sacrificed by cervical dislocation at 10 and $30 \mathrm{~min}$ after injection, and a terminal blood sample was obtained. The mouse brains were rapidly removed, homogenized in $2 \mathrm{~mL}$ of $\mathrm{ACN}: \mathrm{H}_{2} \mathrm{O}$ $50 \%-50 \%$ (vol) with $0.06 \mathrm{M}$ ammonium formate to extract parent tracer and radiometabolites, centrifuged at 20,000 $g$ at $4{ }^{\circ} \mathrm{C}$. Resulting supernatants were analyzed by reversephase (RP)-HPLC.

\section{Dynamic PET data analysis}

The 90 min of PET data were binned into 30 frames: four 15-s, four 30-s, three 1-min, two 2-min, five 4 -min, and 12 5 -min frames. Images were reconstructed using the 3D iterative ordered subset expectation maximization (OS-EM) algorithm (with six iterations and 16 subsets) with correction for radioactive decay, deadtime, attenuation, scatter, and randoms [27]. The reconstructed image space consisted of cubic voxels, each $1.22 \mathrm{~mm}^{3}$ in size, and spanning dimensions of $31 \mathrm{~cm} \times 31 \mathrm{~cm}$ (transaxially) and $25 \mathrm{~cm}$ (axially).

The software package PMOD (v3.7, PMOD Technologies Ltd, Zurich, Switzerland) was used for the image processing and subsequent kinetic analysis. The previously acquired T1-weighted brain MRI images for the baboon were co-registered to the reconstructed dynamic PET images acquired in this study. Through manually matching the co-registered MRI to the INIA19 Template and NeuroMaps Atlas for Primate Brain Image Parcellation and Spatial Normalization [28], 13 representative baboon brain volumes of interest (VOIs) were defined, including frontal and temporal gyri, thalamus, hippocampus, caudate, putamen, amygdala, globus pallidus, insula, hypothalamus, cerebellum, corpus callosum, and white matter. Regional time activity curves (TACs) were then generated for both baseline and blocking PET scans using those VOIs.

Next, kinetic modeling was performed based on the TACs and the metabolite-corrected arterial plasma input functions. For brain uptake, the primary outcome

Table 1 Experimental information for $\left[{ }^{18}\right.$ F]FNDP PET scans (baseline and blocking) in baboons

\begin{tabular}{|c|c|c|c|c|c|c|}
\hline Animal & Study & Days after baseline scan & {$\left[{ }^{18} \mathrm{~F}\right] \mathrm{FNDP}$ dose $(\mathrm{MBq})$} & 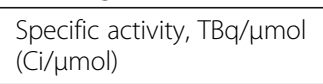 & $\begin{array}{l}\text { FNDP carrier dose, } \\
(\mu \mathrm{g} / \mathrm{kg})\end{array}$ & $\begin{array}{l}\text { AR-9281 dose } \\
(\mathrm{mg} / \mathrm{kg})\end{array}$ \\
\hline Baboon 1 & Baseline & - & 314.13 & $1.30(35.2)$ & $3.2 \times 10^{-3}$ & 0 \\
\hline Baboon 2 & Baseline & - & 247.90 & $2.63(71.2)$ & $1.3 \times 10^{-3}$ & 0 \\
\hline \multirow[t]{4}{*}{ Baboon 3} & Baseline & - & 295.26 & 3.65 (98.6) & $1.1 \times 10^{-3}$ & 0 \\
\hline & Blocking 1 & 27 & 283.42 & $2.87(77.5)$ & $1.3 \times 10^{-3}$ & 1.0 \\
\hline & Blocking 2 & 69 & 294.89 & $2.96(79.9)$ & $1.3 \times 10^{-3}$ & 0.1 \\
\hline & Blocking 3 & 112 & 284.16 & $2.13(57.5)$ & $1.8 \times 10^{-3}$ & 0.02 \\
\hline
\end{tabular}


measure was the regional brain distribution volume $\left(V_{T}\right)$ of $\left[{ }^{18} \mathrm{~F}\right] \mathrm{FNDP}$, defined as concentration of the radiotracer in regional tissue relative to that in blood at equilibrium [29]. We evaluated which compartmental models (e.g., two-tissue-three-compartment (2TCM) or one-tissue-two-compartment (1TCM)) best described the $\left[{ }^{18}\right.$ F]FNDP PET data, using statistical model selection criteria, such as the Akaike information criterion [30]. For comparison, the Logan graphical method $\left(t^{*}=30 \mathrm{~min}\right)$ was also used to compute regional $V_{T}$, as well as generating voxel-wise parametric images of $V_{T}$ [31].

For blocking studies, occupancy of sEH by FNDP was calculated using regional $V_{T}$ values as

$$
\text { Occupancy }=\frac{\Delta V_{T}}{V_{T}^{\text {Baseline }}-V_{\mathrm{ND}}},
$$

where $V_{\mathrm{ND}}$, the distribution volume of nondisplaceable radioligand, was obtained from the Lassen plot, i.e., using a scatterplot of $\Delta V_{T}$ (i.e., baseline $V_{T}$ minus post-blocking $V_{T}$ ) versus baseline $V_{T}$ of all regions [32, 33]. The assumption for this method was that regions showed similar occupancies (i.e., a linear model was supported). When that condition was satisfied, $V_{\mathrm{ND}}$ was given as the intercept of the regression line with the $X$-axis. The non-displaceable binding potential $\left(\mathrm{BP}_{\mathrm{ND}}\right)$ was computed as $V_{T} / V_{\mathrm{ND}}-1$.

\section{Full-body radiation dosimetry for $\left[{ }^{18} \mathrm{~F}\right] \mathrm{FNDP}$ in mice}

Radiation dosimetry for $\left[{ }^{18} \mathrm{~F}\right] \mathrm{FNDP}$ was studied in CD-1 mice (males, 23-27 g) following the procedure of reference [34]. A solution of $3.7 \mathrm{MBq}(0.1 \mathrm{mCi})\left[{ }^{18} \mathrm{~F}\right] \mathrm{FNDP}$ in $0.2 \mathrm{~mL}$ of saline was injected into the lateral tail vein, and groups of mice ( $n=3$ per time point) were euthanized at $15,30,60,120$, and $180 \mathrm{~min}$ after injection. The organs (lungs, heart, kidneys, liver, spleen, intestine, stomach, and brain) were quickly dissected on ice. Left femur and samples of muscle and blood were also collected. The organs were weighed, and the organ radioactivity was measured with an automated gamma counter (LKB Wallac 1282 CompuGamma CS Universal Gamma Counter). All measurements were corrected for decay. The percent injected dose per organ (\%ID/organ) was calculated.

Further analysis was performed commercially (RADAR, Inc, Nashville, TN). In brief, the values of percent of injected activity per organ were fit using SAAM II software [35]. Time integrals of activity were entered into the OLINDA/EXM software [36], using the adult male model. Activity observed in the gastrointestinal (GI) tract was assumed to enter the small intestine and was treated by the standard GI kinetic model. Accumulation of activity was observed in the urinary bladder; activity in the whole body, minus that in the GI tract, was fitted; and the observed biological half time was used in the standard voiding urinary bladder model. The number of disintegrations in the 'remainder of body' was assumed to be equal to $100 \%$ of the activity administered integrated to total decay of ${ }^{18} \mathrm{~F}$, minus the disintegrations in other body organs.

\section{Results}

\section{Baboon PET studies}

\section{Plasma and tissue time-activity curves}

In plasma, the amount of $\left[{ }^{18} \mathrm{~F}\right] \mathrm{FNDP}$ gradually decreased after injection while radiometabolites gradually increased (Fig 2a). The radiometabolism rate was faster in the blocking scans with higher doses (i.e., $1 \mathrm{mg} / \mathrm{kg}$ and 0.1 $\mathrm{mg} / \mathrm{kg}$ ) of AR-9281 than those in the baseline scan and low-dose $(0.02 \mathrm{mg} / \mathrm{kg})$ blocking scan. Figure $2 \mathrm{~b}$ shows the plasma activity with and without metabolite correction for the $0.1 \mathrm{mg} / \mathrm{kg}$ blocking study.

Figure 3 shows the SUV time-activity curves (TACs) of selected brain regions from baseline and blocking scans. The TACs in Fig. 3a present the mean values and standard deviations computed from baseline scans in three baboons. For all regions at baseline, TACs peaked before $15 \mathrm{~min}$ post-injection, and then gradually decreased with time. The results from all three animals were very similar to each other as demonstrated by the small standard deviation.

For blocking scans in Baboon3, when high doses $(0.1$ $\mathrm{mg} / \mathrm{kg}$ and $1 \mathrm{mg} / \mathrm{kg}$ ) AR-9281 were used for blocking, the TACs peaked earlier and decreased rapidly after peaking for all the brain regions, indicating high occupancy of the tracer binding site by AR-9281. When a blocking dose of $0.02 \mathrm{mg} / \mathrm{kg}$ was used, the peaks of the regional TACs were higher than those of the baseline, while decreasing at a faster rate than in the baseline study.

\section{Tissue compartmental model}

Regional $V_{T}$ and $K_{1}$ values given by $1 \mathrm{TCM}, 2 \mathrm{TCM}$ and $V_{T}$ values from the Logan graphical method are listed in Table 2 for the baseline scan. Results show the mean and standard deviation from the three baboons used in this study. The $V_{T}$ values from the 1TCM were smaller than those from the 2TCM and the Logan method. Supplemental Fig S1 compares model-fitted TACs between the 1TCM and 2TCM for Baboon3. The results from the 2TCM matched the measured results while some discrepancies were seen for the 1TCM results. The AIC (Akaike information criteria) values computed from 2TCM were always smaller than the corresponding AIC values computed from 1TCM. A multivariate analysis of variance (MANOVA) was performed where the tissue compartmental model method was an independent variable and the AIC data from each animal was dependent variable. The resulting $P<0.005$ is significant after 

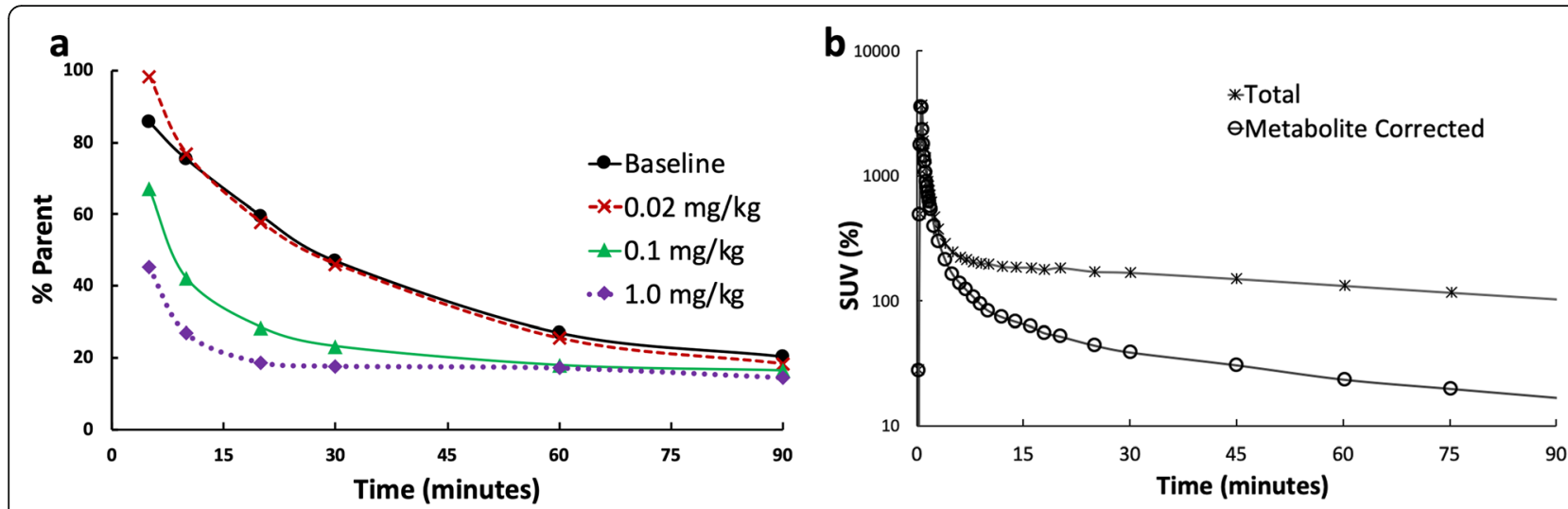

Fig. 2 Radioactive metabolites from four scans (baseline and blocking studies on Baboon3) (a), and plasma activity with and without metabolite correction from blocking scan with $0.1 \mathrm{mg} / \mathrm{kg}$ dose (b)

Bonferroni correction for multiple comparison $(0.05 / 3=$ $0.0133)$, indicating that the $2 \mathrm{TCM}$ is a preferred model for studying $\left[{ }^{18} \mathrm{~F}\right] \mathrm{FNDP}$ uptake in the brain. Table 2 also shows that there is very good agreement between Logan estimated $V_{T}$ and $V_{T}$ estimated from the 2TCM (Pearson's $r=0.99, P<0.001)$. Therefore, the Logan method was used to compute $V_{T}$ parametric images and to compare the baseline and blocking scans.

Figure 4 compares the $V_{T}$ parametric images from baseline and three blocking scans computed using the Logan method for Baboon3. The regional $V_{T}$ values are shown in Fig. 5 for Baboon3. At baseline, the $V_{T}$ values
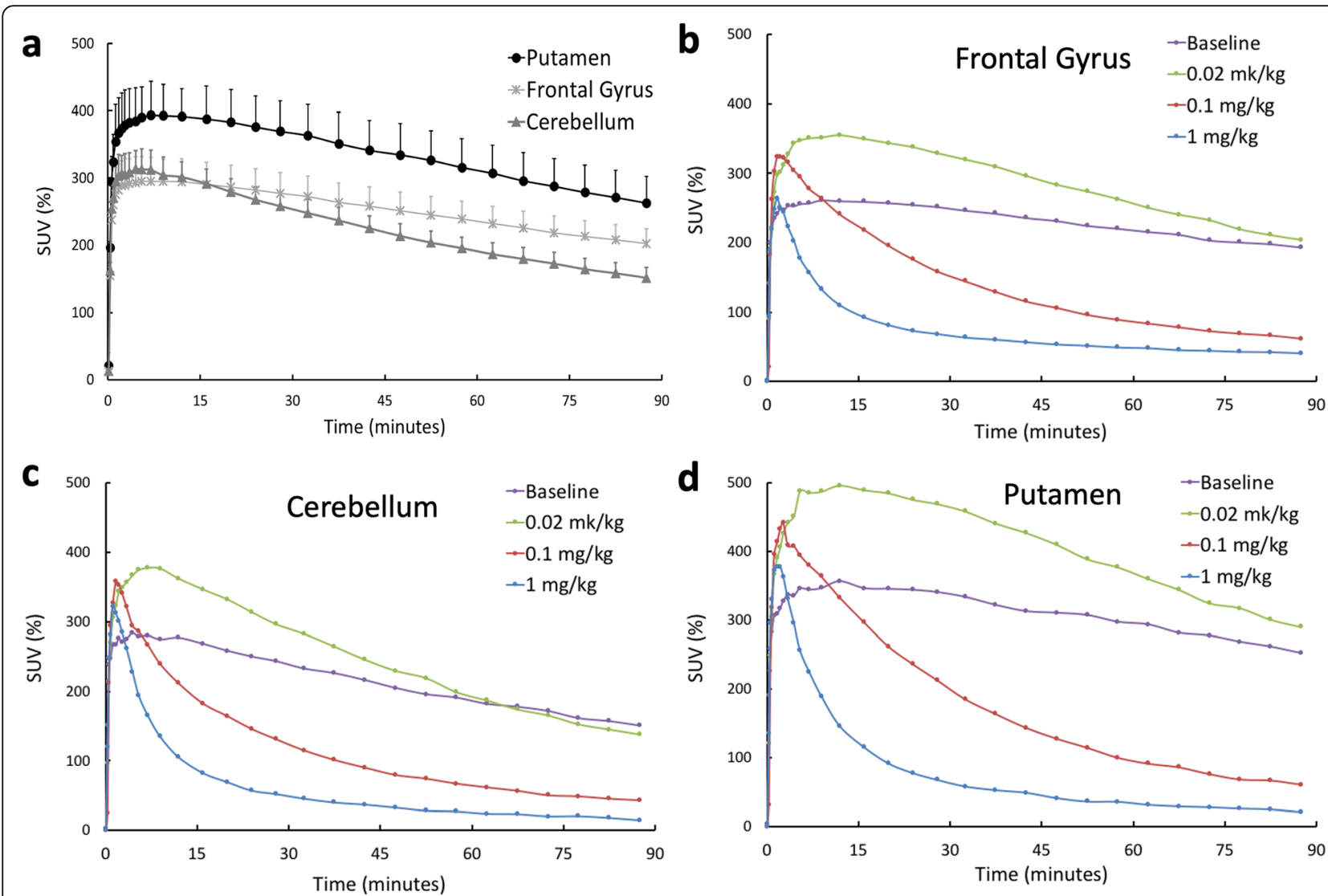

Fig. 3 a The baseline time-activity curves (TACS) of selected brain regions showing mean and standard deviation from baseline scans of three animals. b TACs of frontal gyrus from baseline and three blocking scans (Baboon3). c TACs of cerebellum from baseline and three blocking scans (Baboon3). d TACs of putamen from baseline and three blocking scans (Baboon3) 
Table 2 Estimated parameters from baseline scan of three baboons using different compartmental models

\begin{tabular}{|c|c|c|c|c|c|}
\hline & \multicolumn{2}{|l|}{$2 \mathrm{TCM}$} & \multicolumn{2}{|l|}{$1 \mathrm{TCM}$} & Logan \\
\hline & $\begin{array}{ll}V_{T} \quad(\mathrm{~mL} / \mathrm{mL}) \\
\end{array}$ & $K_{1}\left(\mathrm{~mL} / \mathrm{cm}^{3} / \mathrm{min}\right)$ & $\begin{array}{ll}V_{T} \quad(\mathrm{~mL} / \mathrm{mL}) \\
\end{array}$ & $K_{1}\left(\mathrm{~mL} / \mathrm{cm}^{3} / \mathrm{min}\right)$ & $V_{T} \quad(m L / m L)$ \\
\hline Thalamus & $7.90 \pm 0.74$ & $0.17 \pm 0.03$ & $7.42 \pm 0.36$ & $0.16 \pm 0.03$ & $7.87 \pm 0.55$ \\
\hline Hypothalamus & $8.32 \pm 0.57$ & $0.15 \pm 0.03$ & $7.77 \pm 0.35$ & $0.14 \pm 0.03$ & $8.08 \pm 0.44$ \\
\hline Hippocampus & $11.47 \pm 2.61$ & $0.15 \pm 0.04$ & $10.27 \pm 1.55$ & $0.14 \pm 0.03$ & $10.97 \pm 1.96$ \\
\hline Temporal gyrus & $9.77 \pm 1.02$ & $0.17 \pm 0.03$ & $9.05 \pm 0.41$ & $0.16 \pm 0.03$ & $9.52 \pm 0.57$ \\
\hline Frontal gyrus & $10.50 \pm 1.01$ & $0.18 \pm 0.04$ & $9.58 \pm 0.60$ & $0.16 \pm 0.04$ & $10.29 \pm 0.91$ \\
\hline Corpus callosum & $9.28 \pm 0.90$ & $0.17 \pm 0.03$ & $8.32 \pm 0.91$ & $0.15 \pm 0.03$ & $9.06 \pm 0.99$ \\
\hline Globus pallidus & $9.74 \pm 1.02$ & $0.19 \pm 0.03$ & $9.07 \pm 0.66$ & $0.17 \pm 0.03$ & $9.44 \pm 0.92$ \\
\hline White matter & $9.29 \pm 1.08$ & $0.18 \pm 0.04$ & $8.43 \pm 0.89$ & $0.17 \pm 0.04$ & $9.00 \pm 1.03$ \\
\hline Occipital cortex & $7.82 \pm 1.82$ & $0.18 \pm 0.06$ & $7.39 \pm 1.56$ & $0.17 \pm 0.06$ & $7.67 \pm 1.63$ \\
\hline Cerebellum & $7.66 \pm 0.72$ & $0.19 \pm 0.03$ & $7.33 \pm 0.45$ & $0.18 \pm 0.03$ & $7.63 \pm 0.58$ \\
\hline Amygdala & $12.49 \pm 2.47$ & $0.14 \pm 0.03$ & $10.51 \pm 0.81$ & $0.14 \pm 0.03$ & $11.98 \pm 1.63$ \\
\hline Putamen & $13.80 \pm 2.27$ & $0.23 \pm 0.05$ & $12.87 \pm 1.54$ & $0.22 \pm 0.05$ & $13.32 \pm 1.81$ \\
\hline Caudate & $13.90 \pm 2.28$ & $0.21 \pm 0.05$ & $12.95 \pm 1.44$ & $0.21 \pm 0.05$ & $13.35 \pm 1.94$ \\
\hline Insula & $13.76 \pm 1.42$ & $0.22 \pm 0.05$ & $12.13 \pm 1.08$ & $0.20 \pm 0.05$ & $12.82 \pm 1.32$ \\
\hline AIC & $-38.96 \pm 33.09$ & & $-1.65 \pm 12.24$ & & - \\
\hline
\end{tabular}

*The results show mean and standard deviation computed from 3 baboons' parameters.

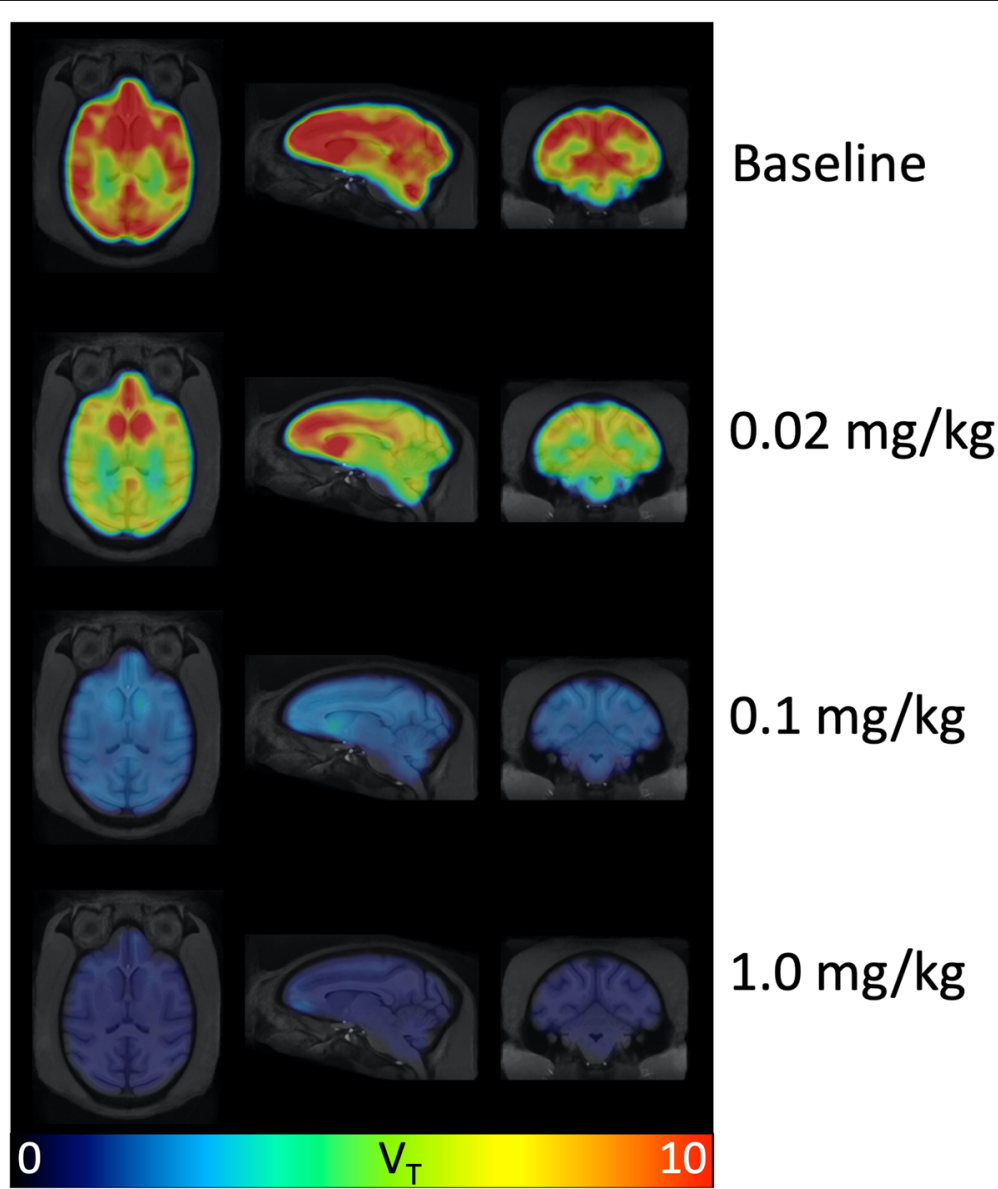

Fig. $4 V_{T}$ parametric images from baseline and three blocking scans with AR-9281 in Baboon3. The Logan graphic method was used to generate the $V_{T}$ map 
had a large variation among different brain regions with the smallest value in the cerebellum and the highest value in the striatum, respectively. Blocking with AR9281 reduced uptake in all brain regions, with the higher doses causing more significant reduction demonstrating high sEH specific binding (see below).

From the 2TCM the estimated $K_{1}$ values were $0.151 \pm$ $0.021 \mathrm{~mL} / \mathrm{cm}^{3} / \mathrm{min}$ for the baseline scan, $0.166 \pm 0.032$ $\mathrm{mL} / \mathrm{cm}^{3} / \mathrm{min}$ for the $1-\mathrm{mg} / \mathrm{kg}$ blocking scan, $0.179 \pm$ $0.026 \mathrm{~mL} / \mathrm{cm}^{3} / \mathrm{min}$ for the $0.1-\mathrm{mg} / \mathrm{kg}$ blocking scan, and $0.170 \pm 0.021 \mathrm{~mL} / \mathrm{cm}^{3} / \mathrm{min}$ for the $0.02-\mathrm{mg} / \mathrm{kg}$ blocking scan, respectively, for Baboon3. The paired Student's $t$ test indicated that there were no significant differences in $K_{1}$ values estimated from the three blocking scans. However, there is a significant difference between $K_{1}$ from baseline and blocking scans, with the $0.1-\mathrm{mg} / \mathrm{kg}$ dose $(P=0.003)$ and the $0.02-\mathrm{mg} / \mathrm{kg}$ dose $(P=0.022)$.

The scatter plot of $\Delta V_{T}$ versus baseline $V_{T}$ is shown in Fig. 6a for the blocking study with $0.1 \mathrm{mg} / \mathrm{kg}$ dose. The results fit a linear model well, with $R^{2}=0.998$, 0.998 , and 0.848 for the blocking dose of $1 \mathrm{mg} / \mathrm{kg}$, $0.1 \mathrm{mg} / \mathrm{kg}$, and $0.02 \mathrm{mg} / \mathrm{kg}$, respectively. Based on the scatter plot, the mean $V_{\mathrm{ND}}$ was estimated to be $0.865 \pm 0.066 \mathrm{~mL} / \mathrm{mL}$. This value is much lower than the $V_{T}$ (from 7.63 to 13.35 in Table 2), indicating lack of an sEH-free region in the baboon brain and low nonspecific binding of $\left[{ }^{18} \mathrm{~F}\right] \mathrm{FNDP}$ across the whole brain. The $\mathrm{BP}_{\mathrm{ND}}$ was calculated $\left(V_{T} / V_{\mathrm{ND}}-1\right)$ to be ranging from 8.37 to 16.02 (unitless), and the specific binding was estimated to be $91.70 \pm 1.74 \%$.
A plot of occupancy versus AR-9281 dose is shown in Fig. $6 \mathrm{~b}$ for all brain regions studied. The estimated occupancy was $99.2 \pm 1.1 \%$ for the $1-\mathrm{mg} / \mathrm{kg}$ dose, $88.6 \pm 1.3 \%$ for the $0.1-\mathrm{mg} / \mathrm{kg}$ dose, and $33.8 \pm 3.8 \%$ for the $0.02-\mathrm{mg} /$ $\mathrm{kg}$ dose, respectively. Because there were only three blocking doses, the $\mathrm{ED}_{50}$ was not estimated.

Further confirmation that $\left[{ }^{18} \mathrm{~F}\right] \mathrm{FNDP}$ specifically targets $\mathrm{sEH}$ is that the regional distribution of $\left[{ }^{18} \mathrm{~F}\right] \mathrm{FNDP}$ in the non-human primate brain agrees with previously published sEH regional expression. The EPHX2 gene encodes $\mathrm{sEH}$. Regional brain distribution of EPHX2 is available from the online protein atlas $[37,38]$. The regional brain uptake of $\left[{ }^{18} \mathrm{~F}\right] \mathrm{FNDP}$ in non-human primate correlates well with mRNA levels of EPHX2 (Fig. 7). This correlation supports the specific binding of $\left[{ }^{18} \mathrm{~F}\right] \mathrm{FNDP}$ at $\mathrm{sEH}$ with the understanding that the correlating tracer binding with protein levels of sEH rather than mRNA levels would be more relevant.

\section{Metabolism of $\left[{ }^{18} \mathrm{~F}\right] \mathrm{FNDP}$ in mouse and baboon}

HPLC radiometabolite analysis of blood samples from CD-1 mice and baboons showed that the parent compound, $\left[{ }^{18} \mathrm{~F}\right]$ FNDP (retention time $=7.8 \mathrm{~min}$ ), was metabolized to two major radiolabeled hydrophilic species (Met-1, retention time $=1-2 \mathrm{~min}$; Met-2, retention time $=5.7 \mathrm{~min}$ ) (Fig. 8). The combined radiometabolites in the plasma reached similar levels of about $50 \%$ of total activity at 30 min after administration of $\left[{ }^{18} \mathrm{~F}\right]$ FNDP in both species, whereas at $90 \mathrm{~min}$ in baboon blood, the combined radiometabolites were

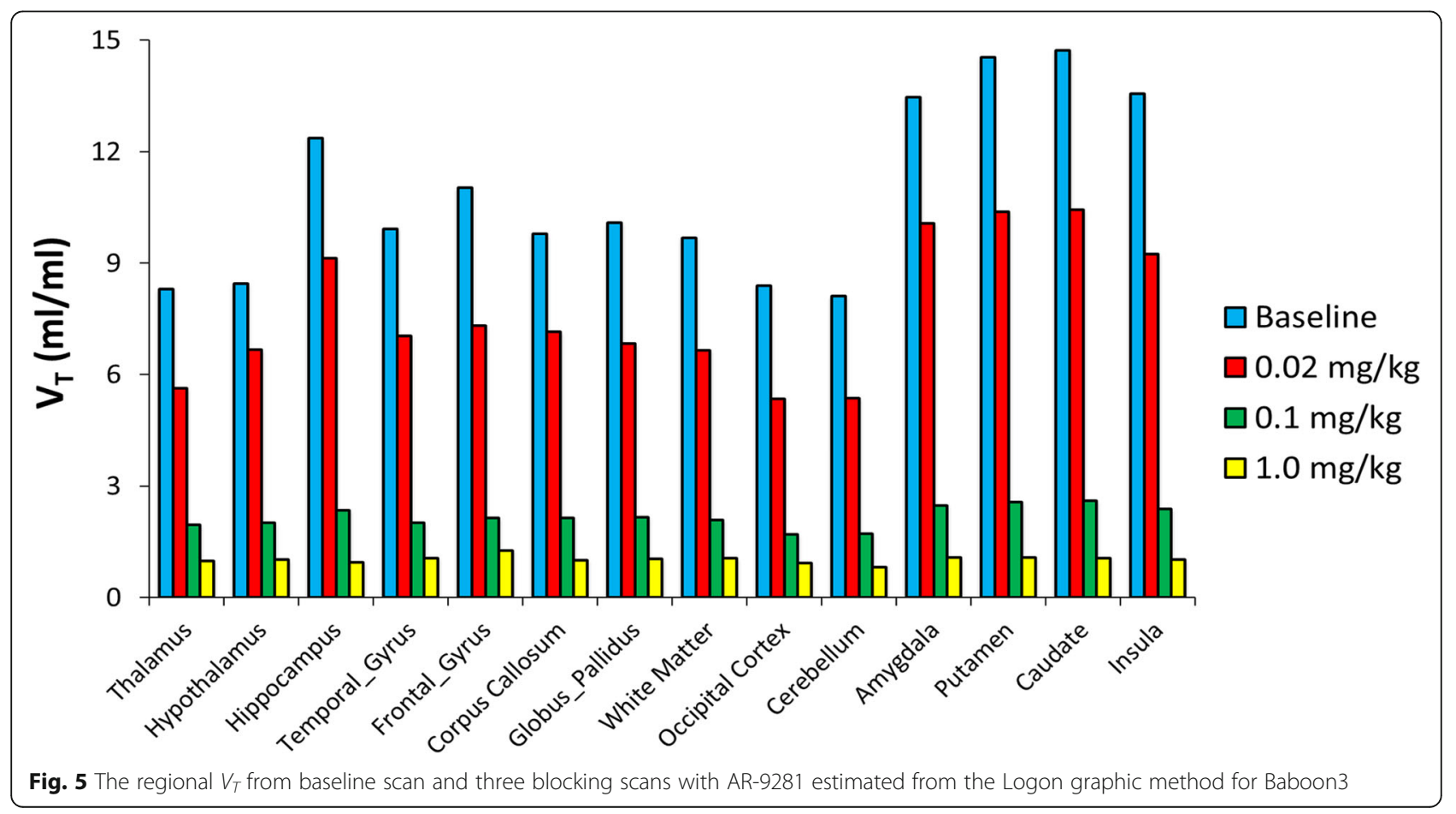



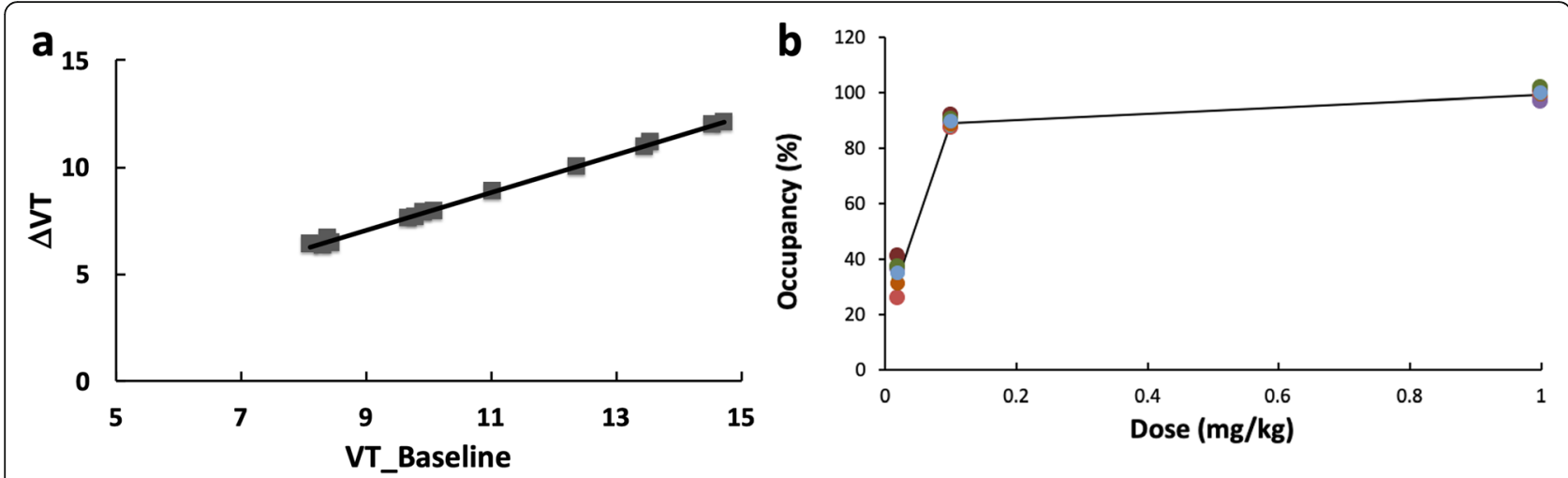

Fig. 6 Scatter plots of $\Delta V_{T}$ vs baseline $V_{T}$ from a blocking study with $0.1 \mathrm{mg} / \mathrm{kg}$ dose (a), and the computed occupancy as a function of the blocking dose for all brain regions (b)

$78 \%$ of total activity. The radiometabolites do not significantly penetrate the blood-brain barrier (BBB) in mice. A low amount of Met-1 entered the mouse brain $(\sim 1.7 \%$ at $30 \mathrm{~min})$, whereas Met-2 was not detectable in the mouse brain, with more than $98 \%$ of unchanged parent present in the brain. See details in Table 3.

\section{Whole-body human radiation dosimetry estimates}

The whole-body $\left[{ }^{18} \mathrm{~F}\right] \mathrm{FNDP}$ distribution data in mice are shown in Supplemental Tables S1\&S2. The mouse distribution results were then extrapolated to humans (adult male model) as shown in Table 4. The estimated effective dose was $0.0317 \mathrm{mSv} / \mathrm{MBq}(0.0117 \mathrm{rem} / \mathrm{mCi})$. The radiation dose of $\left[{ }^{18} \mathrm{~F}\right] \mathrm{FNDP}$ to the bladder, ULI (upper large intestine) wall, small intestine, kidneys, and liver were higher than for the other organs.

\section{Discussion}

$\mathrm{sEH}$ is a bifunctional enzyme with carboxy-terminal hydrolase and amino-terminal lipid phosphatase activities [39]. It is expressed by many cell types in the brain and cerebral blood vessels, including neurons, astrocytes, endothelial cells, and vascular smooth cells [2, 3]. It serves to convert EETs to the corresponding diols within the arachidonic acid cascade. $\mathrm{SEH}$ plays a significant role in

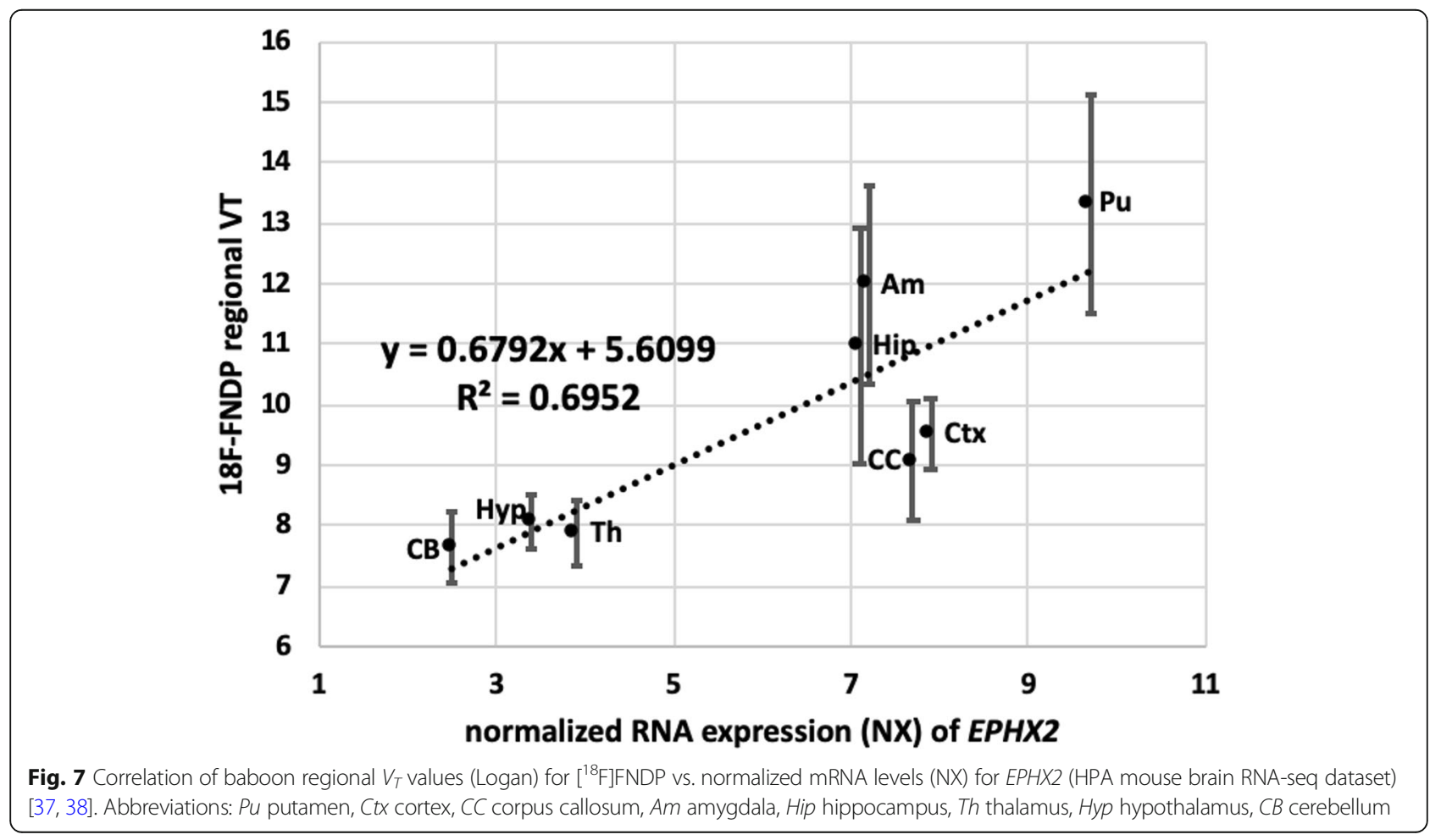




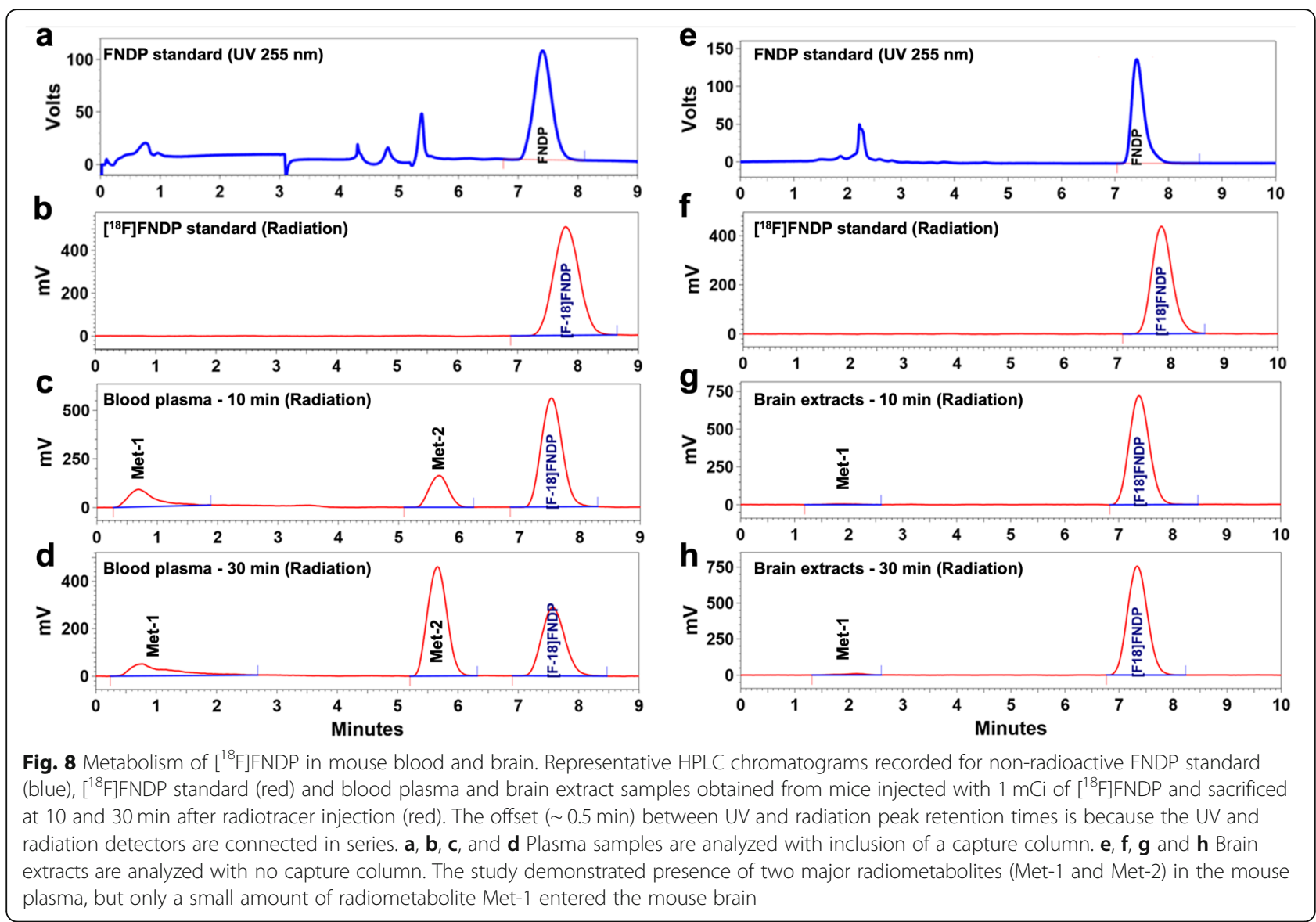

cerebral blood flow autoregulation and neurovascular coupling by regulating the availability of anti-inflammatory EETs in cerebral vasculature $[4,40]$. $\mathrm{sEH}$ has been shown to be upregulated in a variety of neuropsychiatric conditions with a putative inflammatory component, including major depression, bipolar disorder, and schizophrenia [11]. There is also evidence showing that inhibition of $\mathrm{sEH}$ reduces neuronal damage following acute (stroke, hemorrhage) [14] and chronic neurologic insults (Alzheimer's, Parkinson's, and dementia) [41]. sEH is actively pursued both as a biomarker and a drug target in Parkinson's disease, where it tracks

Table 3 HPLC analysis of radiolabeled metabolites of $\left[{ }^{18} \mathrm{~F}\right] \mathrm{FNDP}$ in mouse blood and brain and baboon blood

\begin{tabular}{llll}
\hline & Met-1, \% & Met-2, \% & Parent $\left[{ }^{18} \mathrm{~F}\right] \mathrm{FNDP}, \%$ \\
\hline Mouse blood (10 min) & $11.2 \pm 4.8$ & $25.4 \pm 7.2$ & $63.4 \pm 4.4$ \\
Mouse blood (30 min) & $10.1 \pm 0.9$ & $39.8 \pm 9.8$ & $50.1 \pm 10.5$ \\
Mouse brain (10 min) & $0.8 \pm 0.3$ & Nondetectable & $99.2 \pm 0.3$ \\
Mouse brain (30 min) & $1.7 \pm 0.3$ & Nondetectable & $98.3 \pm 0.3$ \\
Baboon blood (10 min) & $7.2 \pm 1.9$ & $15.8 \pm 2.4$ & $77.0 \pm 3.6$ \\
Baboon blood (30 min) & $16.7 \pm 6.5$ & $36.9 \pm 3.1$ & $46.5 \pm 6.4$ \\
Baboon blood (60 min) & $22.2 \pm 9.3$ & $49.5 \pm 7.7$ & $28.3 \pm 9.3$ \\
Baboon blood (90 min) & $22.3 \pm 8.0$ & $56.0 \pm 7.1$ & $21.8 \pm 7.0$ \\
\hline
\end{tabular}

Table 4 Radiation dosimetry estimates for human (adult male)

\begin{tabular}{lll}
\hline \multicolumn{1}{c}{ Target organ } & Estimated dose \\
\hline Adrenals & $\mathrm{mSv} / \mathrm{MBq}$ & $\mathrm{rem} / \mathrm{mCi}$ \\
Brain & $1.45 \mathrm{E}-02$ & $5.37 \mathrm{E}-02$ \\
Breasts & $5.76 \mathrm{E}-03$ & $2.13 \mathrm{E}-02$ \\
Gallbladder wall & $6.40 \mathrm{E}-03$ & $2.37 \mathrm{E}-02$ \\
LLI (lower large intestine) wall & $2.68 \mathrm{E}-02$ & $9.92 \mathrm{E}-02$ \\
Small intestine & $5.86 \mathrm{E}-02$ & $2.17 \mathrm{E}-01$ \\
Stomach wall & $1.41 \mathrm{E}-01$ & $5.22 \mathrm{E}-01$ \\
ULI (upper large intestine) wall & $1.51 \mathrm{E}-02$ & $5.60 \mathrm{E}-02$ \\
Heart wall & $1.59 \mathrm{E}-01$ & $5.88 \mathrm{E}-01$ \\
Kidneys & $1.58 \mathrm{E}-02$ & $5.86 \mathrm{E}-02$ \\
Liver & $8.92 \mathrm{E}-02$ & $3.30 \mathrm{E}-01$ \\
Lungs & $4.16 \mathrm{E}-02$ & $1.54 \mathrm{E}-01$ \\
Muscle & $8.46 \mathrm{E}-03$ & $3.13 \mathrm{E}-02$ \\
Ovaries & $1.11 \mathrm{E}-02$ & $4.10 \mathrm{E}-02$ \\
Pancreas & $3.36 \mathrm{E}-02$ & $1.24 \mathrm{E}-01$ \\
Red marrow & $1.54 \mathrm{E}-02$ & $5.70 \mathrm{E}-02$ \\
Osteogenic cells & $1.25 \mathrm{E}-02$ & $4.61 \mathrm{E}-02$ \\
Skin & $1.29 \mathrm{E}-02$ & $4.76 \mathrm{E}-02$ \\
Spleen & $6.83 \mathrm{E}-03$ & $2.53 \mathrm{E}-02$ \\
Testes & $1.23 \mathrm{E}-02$ & $4.56 \mathrm{E}-02$ \\
Thymus & $1.58 \mathrm{E}-02$ & $5.83 \mathrm{E}-02$ \\
Thyroid & $7.55 \mathrm{E}-03$ & $2.79 \mathrm{E}-02$ \\
Urinary bladder wall & $6.78 \mathrm{E}-03$ & $2.51 \mathrm{E}-02$ \\
Uterus & $1.66 \mathrm{E}-01$ & $6.13 \mathrm{E}-01$ \\
Total body & $3.31 \mathrm{E}-02$ & $1.22 \mathrm{E}-01$ \\
Effective dose & $1.38 \mathrm{E}-02$ & $5.11 \mathrm{E}-02$ \\
\hline
\end{tabular}


with aggregation of $\alpha$-synuclein and phosphorylated $\alpha$ synuclein in the striatum [8]. Elevations in protein levels of $\mathrm{sEH}$ are on the order of the decreases seen in dopamine transporter (DAT) in Parkinson's disease [8]. Notably, DAT is the target of a widely used clinical imaging study [42]. Accordingly, non-invasive $\left[{ }^{18} \mathrm{~F}\right] \mathrm{FNDP}$ PET imaging of $\mathrm{sEH}$ may facilitate mechanistic understanding of those diseases by providing information of in vivo availability and distribution of $\mathrm{sEH}$ in the human brain. That will enable us to understand better the pathophysiology of vascular components of a variety of disorders including stroke, Alzheimer's dementia, and Parkinson's disease. In addition, pharmacological inhibition of $\mathrm{sEH}$ is under clinical investigation for treatment of hypertension, atherosclerosis, inflammation, and immunological disorders [12, 43]. PET imaging of sEH can also be used for dose selection, occupancy studies, and therapeutic monitoring in patients undergoing treatment with such sEH inhibitors.

\section{Baseline $\left[{ }^{18} \mathrm{~F}\right] \mathrm{FNDP}$ PET in non-human primate brain}

The baboon baseline PET scans in three animals demonstrated high uptake of $\left[{ }^{18} \mathrm{~F}\right] \mathrm{FNDP}$ in most brain regions, in agreement with our previous results [19]. The uptake can be accurately and robustly modeled with a 2TCM. We chose to use the Logan graphical method for analysis because it provided $V_{T}$ values that agreed well with the 2TCM estimates.

\section{Blockade of $\left[{ }^{18} \mathrm{~F}\right] \mathrm{FNDP}$ with AR-9281 in non-human primate brain}

Previous $\left[{ }^{18} \mathrm{~F}\right]$ FNDP blocking studies have been performed with its analog, nor-fluoro-FNDP [19]. Currently, there are many structurally distinct $\mathrm{sEH}$ inhibitors, but a conventional pharmacophore model for $\mathrm{sEH}$ inhibitors is not yet available [44, 45]. Many $\mathrm{sEH}$ inhibitors are urea derivatives, whereas several of the latest compounds, including FNDP, are not urea-based. Therefore, to prove that the very high specific binding of $\left[{ }^{18} \mathrm{~F}\right] \mathrm{FNDP}$ [19] is truly mediated by $\mathrm{sEH}$, we demonstrated that $\left[{ }^{18} \mathrm{~F}\right]$ FNDP binding can be blocked by the structurally different sEH inhibitor, AR-9281 (Fig. 1). AR-9281 is a highly selective and potent $\mathrm{sEH}$ inhibitor $\left(\mathrm{IC}_{50}=8 \mathrm{nM}\right)$ that was previously studied in Phase 2 clinical trials. It is a BBB-permeable drug [14, 20-23]. As shown in Figs. 3, 4 , and 5 , binding of $\left[{ }^{18} \mathrm{~F}\right] \mathrm{FNDP}$ was blocked with AR9281 in a dose-dependent manner and approached full occupancy with a dose of $1.0 \mathrm{mg} / \mathrm{kg}$. Blocking was observed in all brain regions studied. The results of highdose blocking PET- $\left[{ }^{18} \mathrm{~F}\right] \mathrm{FNDP}$ experiments with AR$9281(1 \mathrm{mg} / \mathrm{kg})$ and nor-fluoro-FNDP $(2 \mathrm{mg} / \mathrm{kg}$, previous report [19]) were nearly comparable.

Because sEH inhibitors can increase peripheral vasodilation and reduce blood pressure [46], affecting cerebral blood flow and radiotracer delivery, the rate constant $K_{1}$ estimated from the 2TCM was compared between the baseline and each blocking scan. The estimated $K_{1}$ values were slightly increased for all blocking scans as compared to the $K_{1}$ estimated from the baseline scan, indicating that reductions in $V_{T}$ values with blocking were not induced by increased blood flow and tracer delivery.

The efficient blocking of $\left[{ }^{18} \mathrm{~F}\right] \mathrm{FNDP}$ with two structurally distinct and selective sEH inhibitors, AR-9281 (in this study) and nor-fluoro-FNDP (in our previous study [19]) provides evidence that the radiotracer binding is specific to $\mathrm{sEH}$. The high binding potential $\left(\mathrm{BP}_{\mathrm{ND}}=8-16\right)$ in the baboon brain suggests that $\left[{ }^{18} \mathrm{~F}\right] \mathrm{FNDP}$ may be an excellent radiotracer for PET imaging of brain sEH [47].

\section{$\left[{ }^{18} \mathrm{~F}\right] \mathrm{FNDP}$ radiometabolite study in plasma and brain}

Most PET radiotracers for brain imaging undergo metabolism. Depending on structural properties of the radiometabolites, they may cross the $\mathrm{BBB}$, confounding accurate analysis. Metabolism of xenobiotics normally leads to hydrophilic metabolites via oxidation of the parent xenobiotic or coupling with water-soluble groups with poor BBB permeability [48, 49]. Ideally, for clinically viable PET tracers their radiometabolites should enter the brain only minimally $(<5 \%)$.

RP-HPLC analysis of radiometabolites in mouse and non-human primate plasma demonstrated that in both species, $\left[{ }^{18} \mathrm{~F}\right] \mathrm{FNDP}$ forms the same hydrophilic radiometabolites at a similar rate $(\sim 50 \%$ at $30 \mathrm{~min}$ postinjection). However, most of the radioactivity in the mouse brain was unchanged parent $\left[{ }^{18} \mathrm{~F}\right]$ FNDP (9899\%). Only one radiometabolite (Met-1) entered the mouse brain in a small amount (1.7\%), while the concentration of Met-1 in the mouse blood was $10 \%$. This small amount of radiometabolite Met-1 in the mouse brain is probably due, in part, to the presence of residual blood in the cerebral blood vessels. At the end of the PET scan (60-90 min), Met-1 reached a plateau in an amount of $22 \%$ in the baboon blood. It is reasonable to hypothesize that at the end of the PET scan, the concentration of Met-1 in the baboon brain will be proportional to its concentration in the blood (2.2-times higher than that in the mouse brain) and will reach a value of $\sim 3.7 \%$, while the rest of the brain radioactivity will be parent. Accordingly, we suggest that most radioactivity in the baboon brain is $\left[{ }^{18} \mathrm{~F}\right] \mathrm{FNDP}(>95 \%)$, and mathematical modeling of brain radiometabolites for quantification of the PET scan is unnecessary.

\section{Radiation dosimetry of $\left[{ }^{18} \mathrm{~F}\right] \mathrm{FNDP}$}

A major objective of this preclinical study was to perform full-body biodistribution of $\left[{ }^{18} \mathrm{~F}\right] \mathrm{FNDP}$ in mice and calculate radiation dose estimates for translation of $\left[{ }^{18} \mathrm{~F}\right]$ FNDP to human subjects. The study demonstrated 
that most human organs should receive about $0.01-0.05$ $\mathrm{mSv} / \mathrm{MBq}(0.03$ to $0.15 \mathrm{rem} / \mathrm{mCi})$. The urinary bladder would receive the highest dose, $\sim 0.17 \mathrm{mSv} / \mathrm{MBq}(0.61$ $\mathrm{rem} / \mathrm{mCi}$ ). The effective human dose would be 0.032 $\mathrm{mSv} / \mathrm{MBq}(0.117 \mathrm{rem} / \mathrm{mCi})$. That is similar to other ${ }^{18} \mathrm{~F}$ labeled brain agents for human PET.

In the future, it is also important to study the peripheral distribution and pharmacokinetics of $\left[{ }^{18} \mathrm{~F}\right] \mathrm{FNDP}$. We have shown that the $\left[{ }^{18} \mathrm{~F}\right]$ FNDP is metabolized, and the metabolites are hydrophilic that do not pass BBB. Thus, they will not affect brain imaging. However, those metabolites will have to be considered very carefully with respect to pharmacokinetics relative to the parent when interpreting and quantifying images in the periphery.

\section{Conclusion}

This study demonstrated that $\left[{ }^{18} \mathrm{~F}\right] \mathrm{FNDP}$ can be used for highly specific in vivo PET imaging of sEH in the baboon brain. Dose-escalation blocking studies with AR-9281, a selective $\mathrm{sEH}$ inhibitor that is structurally dissimilar to FNDP, confirmed that uptake of $\left[{ }^{18} \mathrm{~F}\right] \mathrm{FNDP}$ is specific for sEH. $\left[{ }^{18} \mathrm{~F}\right] \mathrm{FNDP}$ PET can provide reliable estimates of $V_{T}$ with a two-tissue-three-compartment model and is suitable for evaluation of sEH inhibitors. In agreement with the high specific binding of $\mathrm{sEH}$, the baboon brain regional distribution of $\left[{ }^{18} \mathrm{~F}\right] \mathrm{FNDP}$ correlates with regional RNA expression of $E P H X 2$, which encodes sEH.

HPLC analysis demonstrated that $\left[{ }^{18} \mathrm{~F}\right] \mathrm{FNDP}$ forms hydrophilic radiometabolites in mouse and baboon plasma. These radiometabolites of $\left[{ }^{18} \mathrm{~F}\right] \mathrm{FNDP}$ minimally enter the animal brain, suggesting that their inclusion in PET image analysis is unnecessary. Radiation dosimetry studies in mice showed that the radiation burden of $\left[{ }^{18} \mathrm{~F}\right] \mathrm{FNDP}$ PET is low and radiotracer is radiologically safe for future human studies.

In summary, $\left[{ }^{18} \mathrm{~F}\right] \mathrm{FNDP}$ is a safe and specific PET imaging agent for $\mathrm{sEH}$ with favorable properties for quantitative imaging in the animal brain. $\left[{ }^{18} \mathrm{~F}\right] \mathrm{FNDP}$ holds promise for translation to human subjects. PET imaging of $\mathrm{sEH}$ with $\left[{ }^{18} \mathrm{~F}\right] \mathrm{FNDP}$ would provide mechanistic information to facilitate understanding of the neurobiology of various brain diseases.

\footnotetext{
Abbreviations

1TCM: One-tissue-two-compartment; 2TCM: Two-tissue-three-compartment: 3D: Three dimensional; AD: Alzheimer's disease; AR-9281: 1-(1-Acetylpiperidin-4-yl)-3-adamantan-1-yl-urea; BBB: Blood-brain barrier; $\mathrm{BP}_{\mathrm{ND}}$ : Nondisplaceable binding potential; EETs: Epoxyeicosatrienoic acids; $\left[{ }^{18} \mathrm{~F}\right] \mathrm{FNDP}: \mathrm{N}$ (3,3-diphenylpropyl)-6- ${ }^{18}$ F-fluoronicotinamide; FWHM: Full width at half maximum; HRRT: High-resolution research tomograph; HPLC: Highperformance liquid chromatography; MANOVA: Multivariate analysis of variance; PET: Positron emission tomography; sEH: Soluble epoxide hydrolase; TAC: Time-activity curves; VCl: Vascular cognitive impairment; VOI: Volume of interest; $V_{N D}$ : Distribution volume of non-displaceable radioligand; $V_{T}$

: Distribution volume
}

\section{Acknowledgements}

We are grateful to Paige Finley, MS and James Engles, MS for assistance with animal experiments and the staff of the Johns Hopkins PET Center for PET imaging expertise. We are also grateful to Martin J Stumpf, MS for proofreading the manuscript.

\section{Authors' contributions}

$\mathrm{AH}$ and MP jointly developed the concept of the manuscript. YD and $\mathrm{AH}$ performed PET data analysis and were highly involved in the writing of the manuscript. $\mathrm{AH}, \mathrm{IM}$, and CF performed mice study and ex vivo measurement. WL performed radiometabolite HPLC analysis and plasma counting. $\mathrm{AH}, \mathrm{FH}$, and $\mathrm{RD}$ performed radiotracer synthesis and labeling. All authors were involved in the writing and proof reading of the manuscript.

\section{Funding}

This research was supported by NIH grant AG054802.

Availability of data and materials

Please contact the authors for data request.

Ethics approval and consent to participate

All experimental animal protocols were performed in accordance with relevant federal and state laws and institutional guidelines and approved by the Animal Care and Use Committee of the Johns Hopkins Medical Institutions.

\section{Consent for publication}

Not applicable

\section{Competing interests}

MGP and AGH are co-inventors on a US patent covering $\left[{ }^{18} \mathrm{~F}\right] \mathrm{FNDP}$ and as such are entitled to a portion of any licensing fee and royalty generated by this technology.

Received: 3 April 2020 Accepted: 9 June 2020

Published online: 22 June 2020

\section{References}

1. Spector AA, Norris AW. Action of epoxyeicosatrienoic acids on cellular function. Am J Physiol Cell Physiol. 2007;292(3):C996-1012.

2. Sura $P$, et al. Distribution and expression of soluble epoxide hydrolase in human brain. J Histochem Cytochem. 2008;56(6):551-9.

3. Marowsky A, et al. Distribution of soluble and microsomal epoxide hydrolase in the mouse brain and its contribution to cerebral epoxyeicosatrienoic acid metabolism. Neuroscience. 2009;163(2):646-61.

4. Nelson JW, et al. Role of soluble epoxide hydrolase in age-related vascular cognitive decline. Prostaglandins Other Lipid Mediat. 2014;113-115:30-7.

5. Hashimoto K. Role of soluble epoxide hydrolase in metabolism of PUFAs in psychiatric and neurological disorders. Front Pharmacol. 2019;10:36.

6. Shih PB, et al. Dysregulation of soluble epoxide hydrolase and lipidomic profiles in anorexia nervosa. Mol Psychiatry. 2016;21(4):537-46.

7. Shen $Y$, et al. Anti-inflammatory treatment with a soluble epoxide hydrolase inhibitor attenuates seizures and epilepsy-associated depression in the $\mathrm{LiCl}$ pilocarpine post-status epilepticus rat model. Brain Behav Immun. 2019.

8. Ren $\mathrm{Q}$, et al. Soluble epoxide hydrolase plays a key role in the pathogenesis of Parkinson's disease. Proc Natl Acad Sci U S A. 2018;115(25):E5815-23.

9. Qin X, et al. Soluble epoxide hydrolase deficiency or inhibition attenuates MPTP-induced parkinsonism. Mol Neurobiol. 2015:52(1):187-95.

10. Ren $\mathrm{Q}$, et al. Gene deficiency and pharmacological inhibition of soluble epoxide hydrolase confers resilience to repeated social defeat stress. Proc Natl Acad Sci U S A. 2016;113(13):E1944-52.

11. Swardfager W, et al. Metabolic/inflammatory/vascular comorbidity in psychiatric disorders; soluble epoxide hydrolase (sEH) as a possible new target. Neurosci Biobehav Rev. 2018;87:56-66.

12. Shen HC, Hammock BD. Discovery of inhibitors of soluble epoxide hydrolase: a target with multiple potential therapeutic indications. J Med Chem. 2012;55(5):1789-808.

13. Iliff JJ, Alkayed NJ. Soluble epoxide hydrolase inhibition: targeting multiple mechanisms of ischemic brain injury with a single agent. Future Neurol. 2009;4(2):179-99. 
14. Ingraham RH, Gless RD, Lo HY. Soluble epoxide hydrolase inhibitors and their potential for treatment of multiple pathologic conditions. Curr Med Chem. 2011;18(4):587-603.

15. Yu D, et al. Soluble epoxide hydrolase-derived linoleic acid oxylipins in serum are associated with periventricular white matter hyperintensities and vascular cognitive impairment. Transl Stroke Res. 2019;10(5):522-33.

16. Silbert LC, et al. Trajectory of white matter hyperintensity burden preceding mild cognitive impairment. Neurology. 2012;79(8):741-7.

17. Morris E, et al. Diagnostic accuracy of ${ }^{18} \mathrm{~F}$ amyloid PET tracers for the diagnosis of Alzheimer's disease: a systematic review and meta-analysis. Eur J Nucl Med Mol Imaging. 2016;43(2):374-85.

18. Couto PJ, Millis RM. PET imaging of epigenetic influences on Alzheimer's disease. Int J Alzheimers Dis. 2015;2015:575078.

19. Horti AG, et al. 18F-FNDP for PET imaging of soluble epoxide hydrolase. J Nucl Med. 2016:57(11):1817-22

20. Whitcomb R, et al. AR9281, a soluble epoxide hydrolase inhibitor-efficacy in a DIO mouse model plus pharmacokinetics and pharmacodynamics in mice and men. Diabetes. 2009;58:A165.

21. Wong K, et al. A novel inhibitor of soluble epoxide hydrolase, AR9281, improves glucose homeostasis in diet-induced obese mice. Diabetes. 2009; 58:A121.

22. Anandan SK, et al. 1-(1-Acetyl-piperidin-4-yl)-3-adamantan-1-yl-urea (AR9281) as a potent, selective, and orally available soluble epoxide hydrolase inhibitor with efficacy in rodent models of hypertension and dysglycemia. Bioorganic \& Medicinal Chemistry Letters. 2011;21(3):983-8.

23. Chen D, et al. Pharmacokinetics and pharmacodynamics of AR9281, an inhibitor of soluble epoxide hydrolase, in single- and multiple-dose studies in healthy human subjects. J Clin Pharmacol. 2012;52(3):319-28.

24. Azad BB, et al. An optimized radiosynthesis of $\left[{ }^{18} \mathrm{~F}\right] \mathrm{FNDP}$, a PET radiotracer for jmaging soluble epoxide hydrolase (sEH). J Labelled Comp Radiopharm. 2018. https://doi.org/10.1002/jlcr.3620

25. Sossi $\bigvee$, et al. IEEE Nuclear Science Symposium Conference Record. 2005: 2195-9

26. Coughlin JM, et al. The distribution of the alpha7 nicotinic acetylcholine receptor in healthy aging: an in vivo positron emission tomography study with $\left[{ }^{18}\right.$ F]ASEM. Neuroimage. 2018;165:118-24.

27. Rahmim A, et al. Statistical dynamic image reconstruction in state-of-the-art high-resolution PET. Phys Med Biol. 2005;50(20):4887-912

28. Rohlfing T, et al. The INIA19 template and NeuroMaps atlas for primate brain image parcellation and spatial normalization. Front Neuroinform. 2012; $6: 27$.

29. Innis RB, et al. Consensus nomenclature for in vivo imaging of reversibly binding radioligands. J Cereb Blood Flow Metab. 2007;27(9):1533-9.

30. Carson, R.E., Parameter estimation in positron emission tomography. Positron emissoin tomography and autoradiography:principles and applications for the brain and heart, 1986. New York: Raven Press: p. 347-390.

31. Logan J, et al. Graphical analysis of reversible radioligand binding from time-activity measurements applied to $\left[\mathrm{N}-{ }^{11} \mathrm{C}\right.$-methyl]-(-)-cocaine PET studies in human subjects. J Cereb Blood Flow Metab. 1990;10(5):740-7.

32. Lassen NA, et al. Benzodiazepine receptor quantification in vivo in humans using $\left[{ }^{11} \mathrm{C}\right]$ flumazenil and PET: application of the steady-state principle. J Cereb Blood Flow Metab. 1995;15(1):152-65.

33. Cunningham VJ, et al. Measuring drug occupancy in the absence of a reference region: the Lassen plot re-visited. J Cereb Blood Flow Metab. 2010;30(1):46-50.

34. Kuwabara $H$, et al. Imaging a $4 \beta 2$ nicotinic acetylcholine receptors ( $\mathrm{nAChRs)}$ in baboons with $\left[{ }^{18} \mathrm{~F}\right] \mathrm{XTRA}$, a radioligand with improved specific binding in extra-thalamic regions. Mol Imaging Biol. 2017;19(2):280-8.

35. Barrett PH, et al. SAAM II: Simulation, Analysis, and Modeling Software for tracer and pharmacokinetic studies. Metabolism. 1998;47(4):484-92.

36. Stabin MG, Sparks RB, Crowe E. OLINDA/EXM: the second-generation personal computer software for internal dose assessment in nuclear medicine. J Nucl Med. 2005;46(6):1023-7.

37. The human protein atlas. p. https://www.proteinatlas.org/ENSG0000012 0915-EPHX2/brain

38. Uhlen, M., et al., A pathology atlas of the human cancer transcriptome. Science, 2017. 357(6352)

39. Lee HT, et al. Genetic deletion of soluble epoxide hydrolase delays the progression of Alzheimer's disease. J Neuroinflammation. 2019;16(1):267.

40. Imig JD, et al. Cytochrome P450 eicosanoids and cerebral vascular function. Expert Rev Mol Med. 2011;13:e7.
41. Kodani SD, Morisseau C. Role of epoxy-fatty acids and epoxide hydrolases in the pathology of neuro-inflammation. Biochimie. 2019;159:59-65.

42. Benamer, H.T.S., et al., Accurate differentiation of parkinsonism and essential tremor using visual assessment of $\left[{ }^{123} \mathrm{l}\right]$-FP-CIT SPECT imaging: the $\left[{ }^{123} \mathrm{l}\right]$-FPCIT study group. Mov Disord, 2000. 15(3): p. 503-510.

43. Shen HC. Soluble epoxide hydrolase inhibitors: a patent review. Expert Opin Ther Pat. 2010;20(7):941-56.

44. Tripathi N, et al. Discovery of novel soluble epoxide hydrolase inhibitors as potent vasodilators. Sci Rep. 2018:8(1):14604.

45. Anandan SK, et al. Non-urea functionality as the primary pharmacophore in soluble epoxide hydrolase inhibitors. Bioorg Med Chem Lett. 2009:19(4): 1066-70.

46. Harris TR, et al. The potential of soluble epoxide hydrolase inhibition in the treatment of cardiac hypertrophy. Congest Heart Fail. 2008;14(4):219-24.

47. Friden $\mathrm{M}$, et al. Identification of positron emission tomography (PET) tracer candidates by prediction of the target-bound fraction in the brain. EJNMMI Res. 2014:4(1):50.

48. Danielson PB. The cytochrome P450 superfamily: biochemistry, evolution and drug metabolism in humans. Curr Drug Metab. 2002;3(6):561-97.

49. King CD, et al. UDP-glucuronosyltransferases. Curr Drug Metab. 2000;1(2): 143-61.

\section{Publisher's Note}

Springer Nature remains neutral with regard to jurisdictional claims in published maps and institutional affiliations.

\section{Submit your manuscript to a SpringerOpen ${ }^{\circ}$ journal and benefit from:}

- Convenient online submission

- Rigorous peer review

- Open access: articles freely available online

- High visibility within the field

- Retaining the copyright to your article

Submit your next manuscript at $>$ springeropen.com 